\title{
RACIONALIDADE AMBIENTAL SULEADA PELO ECOSSOCIALISMO NA PRÁXIS DOS EDUCADORES AMBIENTAIS
}

\author{
Leandro Carneiro ${ }^{1}$
}

\section{RESUMO}

O presente artigo é parte das reflexões parciais de uma dissertação de mestrado em educação, do Programa de Pós-Graduação Contextos Contemporâneos e Demandas Populares (PPGEduc), da Universidade Federal Rural do Rio de Janeiro. O artigo versa a respeito da busca por respostas em relação a qual tipo de sociedade os educadores ambientais críticos, transformadores e emancipatórios podem incentivar, fundamentados em novas epistemologias, como o ecossocialismo e a racionalidade ambiental. Como estratégias de superação da atual policrise, principalmente nas suas faces mais nefastas e apocalípticas, como a miséria e as catástrofes ambientais.

Palavras-chave: Ecossocialismo; Racionalidade Ambiental; Sociedade Sustentável.

\section{ENVIRONMENTAL RATIONALITY SOUTHING BY ECOSOCIALISM IN THE PRACTICE OF ENVIRONMENTAL EDUCATORS}

\begin{abstract}
This article is part of the partial reflections of a master's degree dissertation in Education, from the Graduate Program in Contemporary Contexts and Popular Demands (PPGEduc), Federal Rural University of Rio de Janeiro. The article deals with the search for answers in relation to which type of society critical, transformative and emancipatory environmental educators can encourage, based on new epistemologies such as ecossocialism and environmental rationality. As strategies to overcome the current polycrisis, especially in its most nefarious and apocalyptic faces, such as poverty and environmental disasters.
\end{abstract}

Keywords: Ecosocialism; Environmental Rationality; Sustainable Society.

\section{Introdução}

1 Especialista em Planejamento e educação ambiental. Mestrando em educação. Orientando do Professor Dr. Mauro Guimarães. Universidade Federal Rural do Rio de Janeiro (UFRRJ). leandrocarneiro13@gmail.com. 
No presente artigo é desenvolvida uma discussão e um arcabouço teórico que subsidie o direcionamento da práxis de educadores ambientais críticos, transformadores e emancipatórios, a partir das referências do ecossocialismo e da racionalidade ambiental.

A educação ambiental crítica, transformadora e emancipatória parte do pressuposto que vivemos uma crise civilizatória e que essa realidade precisa ser transformada. Sendo assim, não podemos apenas constatar os problemas da realidade atual. Ou, apenas realizar uma crítica a este modelo civilizatório e ansiar uma transformação, precisamos saber: transformar para o quê?

Ou ainda, esses educadores ambientais críticos tendem a refletir em um novo modelo de sociedade. Desse modo, cabe a seguinte indagação: Qual sociedade é essa que tal educador pretende incentivar a construção?

A reflexão teórica a seguir será permeada por uma reflexão em relação à crise civilizatória e a práxis do educador ambiental crítico, transformador e emancipatório nesse contexto.

Apresentar-se-á uma crítica à modernidade ocidental, produtora da chamada policrise tendo como contraponto a proposição de uma sociedade ambientalmente sustentável. E, mais adiante serão construídas diretrizes teóricas que embasam a formação de educadores ambientais críticos, como interventores no processo de construção de uma sociedade sustentável.

Executar-se-á uma correlação epistemológica entre o ecossocialismo, segundo Michael Löwy e a chamada racionalidade ambiental, segundo Enrique Leff. De maneira que possamos estabelecer elos epistêmicos entre alguns de seus principais pressupostos e um vislumbre acerca de qual tipo de sociedade esse educador ambiental crítico, transformador e emancipatório pretende incentivar a construção. Sempre sinalizando a importância da vontade e da capacidade de sonhar com outras realidades sociais mais equânimes e com relações cada vez mais harmoniosas entre sociedade e natureza.

\section{Metodologia}

As reflexões teóricas aqui presentes são de caráter crítico-dialéticas. Somadas com orientações teórico-metodológicas da concepção críticoemancipatória. $O$ trabalho foi realizado com levantamentos bibliográficos e 
articulações dialógicas entre importantes conceitos e teorias, concernentes à epistemologia da educação ambiental crítica.

Aqui é retratada a chamada crise civilizatória e alguns dos principais desafios do educador ambiental. A referida crise civilizatória é corporificada pela chamada modernidade ocidental. A qual, já não pode ser vista como única fonte de interpretação da realidade. E por isso, novas fontes e novas perspectivas epistemológicas precisam ser conhecidas e empregadas como novas lentes interpretativas desta realidade, principalmente a realidade daqueles que vivem por estas paragens mais ao sul dos grandes centros geopolíticos.

\section{Crise civilizatória e novas perspectivas com o ecossocialismo e a racionalidade ambiental}

Inicialmente poder-se-ia supor que tentamos entender a atualidade sob a ótica conceitual de período de transição. Não é esse o caso. Na realidade, o pressuposto básico da análise remete-nos a mudanças sentidas por todos nós, os contemporâneos dos fatos; desconhecedores, obviamente, do resultado proporcionado por eles, mas acompanhando-os cotidianamente.

Atualmente, de modo feliz e também paradoxal, é um tempo de vigorosa aceitação de que ações devem ser desencadeadas com uma certa urgência, em função da degradação acelerada dos mananciais - aqui entendidos em sentido lato - que fornecem suporte à vida, e, sem os quais, a existência de todo ser vivo é impossível. Tais ações são atos com objetivo, seu resultado é uma alteração no meio e no próprio agente, concomitantes ao cumprimento de regras e um gasto de energia. Trata-se de um modo paradoxal porque representa ameaças à nossa existência, mas também oportunidades de transformação, como aquelas que podem aparecer a partir dos preceitos ecossocialistas e também da racionalidade ambiental.

As ações podem ser distinguidas entre "técnicas, formais e simbólicas e ideológicas" (Braun e Joerges apud Santos, 1996, p.66). As ações técnicas são aquelas que delineiam as maneiras de transformar a natureza. As ações formais tendem a respeitar regras jurídicas, econômicas e científicas. As ações simbólicas são identificadas por um caráter afetivo, emocional, ritualístico ou 
cultural. Todas ocorrem simultaneamente, com destaque para uma ou para a outra dependendo do momento.

A crescente conscientização do quadro supramencionado fornece aos atores sociais da atualidade a clareza de que algumas certezas seculares como consumo ilimitado e desenvolvimento econômico a qualquer custo - não mais se sustentam, ou seja: nós vivenciamos coisas que não são mais e coisas que não são ainda.

Ademais, precisamos enfatizar que uma série de mudanças em nossas ações precisam ser realizadas urgentemente.

Pela gravidade da situação socioambiental em todo o mundo, assim como no Brasil, já se tornou categórica a necessidade de implementar a EA para as novas gerações em idade de formação de valores e atitudes, como também para a população em geral, pela emergência em que nos encontramos. (GUIMARÃES, 2015, p. 34).

Se os indivíduos formam indubitavelmente a base constitutiva de qualquer sociedade, eles, por sua vez, de forma isolada, não têm condições de enfrentarem e modificarem as estruturas presentes naquele arranjo social. Somente o coletivo possui força suficiente para fazê-lo; mesmo porque, toda sociedade é mais do que a simples soma dos indivíduos que a compõem.

Dessa realidade decorre que: mesmo que individualmente possamos ter a clareza das mazelas presentes na sociedade - como, por exemplo, "o modelo de desenvolvimento da sociedade moderna se mostra claramente esgotado por ser insustentável ambientalmente (em sua dimensão biológica e social) " (GUIMARÃES, 2010, p. 17) -, precisamos arregimentar forças para combatê-lo, tendo como principal arma a união de um número expressivo de indivíduos que possuam o mesmo objetivo.

É imprescindível atentar para os riscos aos quais a humanidade passou a ser intensamente submetida, principalmente nas mais recentes quatro ou cinco décadas. Segundo o geógrafo Carlos Walter Porto Gonçalves "Estamos, sim, diante de uma mudança de escala na crise atual de escassez (por poluição) do ar, de escassez (por poluição) de água, de escassez (limites) dos minerais (...) de perda dos solos (limites) ..." (PORTO-GONÇALVES, 2016, p. 32). 
A verdade é que vivemos um momento de uma enorme crise civilizatória. Uma "poli crise"; na medida em que esta é uma crise ecológica, mas também humanitária, socioeconômica e ética.

As notícias envolvendo tragédias e mais tragédias ambientais são cada vez mais recorrentes. Não é mais possível crer que tudo vai bem ou que logo surgirá uma solução tecnológica para enfrentar as dificuldades as quais somos submetidos. Daí a necessidade eminente de aprofundarmos os estudos e modificarmos as práticas em relação ao meio ambiente.

É notório que, seja qual for o projeto (ou projetos) que se afirme a partir do mundo-que-está-aí, terá que incorporar a dimensão ambiental, até pelos riscos que o capitalismo - sobretudo no período neoliberal dos últimos trinta anos - colocou para a humanidade e para o planeta. (PORTO-GONÇALVES, 2016, p. 19).

É progressivamente e cada vez mais claro o caráter altamente destrutivo do sistema em que vivemos. O caso dos vazamentos de rejeitos da mineração no Rio Doce, em 2015 é um triste exemplo. O capitalismo tem alardeado muitos desenvolvimentos; porém, associados a eles, são verificadas imensas destruições nas escalas locais e também globais.

\begin{abstract}
As atuais crises econômica e ecológica são parte de uma conjuntura histórica mais geral: estamos enfrentando uma crise do presente modelo de civilização, a civilização ocidental moderna capitalista/industrial, baseada na expansão e acumulação ilimitada de capital, na 'mercantilização de tudo', na intensa exploração do trabalho e da natureza, no individualismo e competição brutais, e na destruição massiva do meio ambiente. A crescente ameaça de ruptura do equilíbrio ecológico aponta para um cenário catastrófico - 0 aquecimento global - que coloca em perigo a sobrevivência mesma da espécie humana. Enfrentamos uma crise de civilização que demanda uma transformação radical (LÖWY, 2009, p. 50).
\end{abstract}

A partir da ampliação dos conhecimentos e das percepções em relação ao tamanho do problema sobre nossos ombros, é imprescindível uma avaliação crítica em relação ao sistema capitalista em que vivemos.

Cada um percebe ou poderia perceber essa crise ecológica não apenas no ambiente em que vive, mas no próprio ambiente do seu corpo e no próprio ambiente familiar. $\mathrm{Na}$ medida em que, mais e mais males são notados na nossa saúde, mesmo com o ritmo das inovações tecnológicas na área médica/hospitalar/farmacêutica. Em relação a isso alguns poderiam retrucar e afirmar que hoje a expectativa de vida (ou esperança de vida ao nascer) da 
humanidade aumentou consideravelmente. Mas, a expectativa de vida de qual parte da humanidade aumentou? Esse aumento representa mais anos de vida sem problemas de saúde? E mais, será que esse aumento na expectativa de vida também não foi apenas uma elevação no tempo em que nos tornamos consumidores de mais e mais medicamentos das poderosas indústrias farmacêuticas?

Os lucros são acumulados por alguns pequenos grupos de sujeitos que herdam fortunas ou aqueles considerados "mais capazes" na realização dessa acumulação capitalista. Contudo, os prejuízos são sentidos por toda a população mundial. Por exemplo, quando tratamos das poluições realizadas no ar. Conforme o passar dos anos a qualidade do ar em cidades como São Paulo piora consideravelmente, segundo dados do Sistema de Informações de Qualidade do Ar da Companhia Ambiental do Estado de São Paulo (Cetesb), e o número de pessoas com doenças respiratórias só tende a crescer. Até mesmo em cidades como o Rio de Janeiro onde se tinha uma ideia, no senso comum, de que a circulação do ar, devido à proximidade com o mar, poderia contribuir para evitar uma acumulação de gases nocivos, vem se registrando taxas crescentes de poluição atmosférica.

Muitas empresas de países mais ricos seguem os rigorosos padrões de exigências ambientais nos seus países de origem (a maioria europeus). Mas, suas práticas nos países em condições mais precárias (populações de países pobres) remontam às práticas realizadas há anos atrás, quando a única preocupação era a produção e o número de pessoas empregadas. Dessa forma, acabam proporcionando desastres de proporções apocalípticas, como no caso do maior crime ambiental da história do Brasil até então, o vazamento de resíduos tóxicos da mineração pertencentes à Samarco (Uma empresa cujas donas são a Vale do Rio Doce e empresa australiana PHP).

Existe uma fantasiosa esperança de que pode existir um capitalismo menos destruidor em relação ao meio ambiente e também no que se refere às questões socioeconômicas. Algo do tipo a permitir um consumo com a consciência um pouco mais tranquila. É a ideia de continuar comprando e comprando, a utilizar montes de embalagens, mas que sejam biodegradáveis. 
A elevada concentração de riquezas nas posses de um número bem reduzido de pessoas físicas e pessoas jurídicas, é um outro forte indício dos problemas relacionados ao sistema que vivemos.

Cabe uma crítica ao consumismo e a insuficiência da mesma. Trata-se de apenas uma crítica ao consumismo como uma enfermidade e, a continuidade do mesmo como um hábito fortemente ligado ao sistema capitalista.

Não é possível ignorar a ligação imediata entre o produtivismo e 0 capitalismo. E deste, com o consumismo e a ostentação de bens quase que imediatamente inúteis, seja pela obsolescência programada, seja simplesmente pela mudança na moda. Não é nada responsável a adoção de ecotaxas, ainda mais em cenários como os dos países subdesenvolvidos onde manobras jurídicas acabam por procrastinar a aplicação dessas ecotaxas ou até mesmo acabam por isentar o multado do pagamento das mesmas.

Os crescentes casos das chamadas crises humanitárias, como aqueles que têm assolado grandes número de habitantes do continente africano, no que se refere às intermináveis guerras civis e atentados terroristas (Vide Boko Haram), à falta de acesso à água potável e as lastimáveis carências alimentares. Ou, ainda, as crises relacionadas aos fluxos migratórios internos e externos naquele continente, mas também na Síria, em Mianmar e Bangladesh.

A proposta do ecossocialismo é relativamente mais recente, quase paralela ao agravamento dos danos ambientais em escala planetária, promovidos pela nova onda neoliberal. Vários estudiosos praticantes da crítica marxistas, como Manuel Sacristán, André Gorz e Fieder Otto Wolf desenvolveram essa maneira de pensar/agir e realizaram publicações de cunho internacional, como o Manifesto Ecossocialista Internacional (2001) e a fundação da Rede Ecossocialista Internacional (2007). Tal proposta envolve uma conduta plenamente anticapitalista, onde apenas a crítica mais ferrenha ou até demagógica ao consumismo são apenas subterfúgios à manutenção do sistema que aí está.

$\mathrm{Na}$ proposta ecossocialista de Michel Löwy encontramos uma associação da crítica marxista do capital e a alternativa socialista, representadas pelo que o autor chama de "vermelhos" e também a crítica ecológica do produtivismo, como os "verdes". Dessa feita, a articulação entre 
os "vermelhos" e os "verdes" " almeja não só a transformação das relações de produção, do aparelho produtivo e do padrão de consumo dominante, mas sobretudo construir um novo tipo civilização" (LÖWY, 2014, p.9). É uma proposta drástica, no sentido de se diferenciar das chamadas variantes produtivistas do socialismo do século $\mathrm{XX}$ e por atacar as raízes do sistema capitalista.

As possibilidades ecossocialistas lançadas por Löwy são exemplificadas na realidade brasileira, com as ações convergentes do socialismo e a ecologia, vivenciadas por Francisco Alves Mendes Filho (O Chico Mendes) - Um grande brasileiro! Precursor das reservas extrativistas; materialização da lógica socialista no sentido da utilização pública da terra (uma reforma agrária dos amazônidas) e também corporificação da dimensão ecológica, no sentido direto da ligação dos povos tradicionais e da Floresta Amazônica e mais adiante, no futuro, da aplicação deste conceito a mais e mais territórios Brasil a fora.

As bases do ecossocialismo partem dos pensamentos de Marx e Engels, mesmo sendo necessário o alerta de que as questões ecológicas não estavam no centro das atenções teóricas dos aparatos argumentativos desses autores. Ou ainda, as questões ecológicas não foram suficientemente desenvolvidas nos seus escritos. É fundamental destacar a importância da crítica ao capitalismo realizada por eles, principalmente no que se refere à construção de uma visão ecológica que se propões à ruptura com o status quo do capitalismo.

A possibilidade de uma ecologia com fortes inspirações marxistas começa a ser evidenciada quando Marx, (1962, p. 62-87 apud Löwy, 2014, p. 22) afirma:

\footnotetext{
Dizer que a vida psíquica e intelectual do homem está indissoluvelmente ligada à natureza não significa outra coisa senão que a natureza está indissoluvelmente ligada com ela mesma, pois o homem é uma parte da natureza.
}

Segundo Löwy, Marx utiliza a teoria valor-trabalho para explicitar a gênese do valor de troca, no contexto do sistema capitalista. A natureza, por outro lado, colabora na formação das verdadeiras riquezas, que não são valores de troca, mas valores de uso. As energias disponibilizadas pela natureza, por exemplo, a energia solar, a qual possui grande importância 
quanto ao valor de uso no que tange a realização da fotossíntese ou ainda a assimilação de vitamina d em nosso organismo.

Há uma crítica por parte de alguns ambientalistas, ao chamado produtivismo socialista, costumeiramente associado ao modelo industrial implementado na antiga União Soviética stalinista - um período de industrialização rápida e de uma inconsequente disputa com o produtivismo capitalista estadunidense; empregadores de combustíveis fósseis em larga escala e investidores desmedidos na indústria armamentista, por influência direta dos disparates associados ao período da Guerra Fria. Na verdade, "O objetivo supremo do progresso técnico para Marx não é o crescimento infinito de bem ("o ter") mas a redução da jornada de trabalho e o crescimento do tempo livre ("o ser") (Löwy, 2014, p.25). Portanto, a crítica de muitos ambientalista não se sustenta, porque Marx rebate exatamente a apologia ao ter e tudo que ele representa quanto ao consumismo.

Em vários textos de Marx são feitas referências a preocupações ecológicas, porém isso acontece de modo isolado. Quando, por exemplo aborda os impactos decorrentes do capital sobre a natureza, no que se refere à perda de fertilidade do solo, a destruição das florestas ou quando demonstra a preocupação com as gerações futuras e a forma de utilização do planeta Terra. Assim:

\footnotetext{
Mesmo uma sociedade inteira, uma nação, enfim, todas as sociedades contemporâneas tomadas em conjunto, não são proprietárias da terra. Elas são apenas ocupantes, usufrutuárias (Nutzniesser), e devem, como bons paters familias, deixá-la em melhor estado para as futuras gerações. (Marx apud Löwy, 2014, p. 35).
}

O pensamento crítico marxista é muito importante no desenvolvimento das reprimendas e rupturas contra o sistema capitalista. Certamente, não podemos isentar totalmente Marx das tergiversações progressistas, mas também não é possível taxá-lo como defensor inequívoco da industrialização desenfreada e irresponsável. Neste sentido, o ecossocialismo se fortalece como uma oportunidade de renovação do pensamento marxista nestes tempos. A deixar bem claro que, esta aliança entre "vermelhos" e "verdes" se propõe a uma ruptura drástica com a ideia de progresso e acumulação linear, bem como com o paradigma técnico/científico industrial e financeiro reinante. Enfim, a 
reorientação das significações e práticas atreladas à ideia de progresso precisam ser reorientadas, quem sabe até suleadas (segundo Paulo Freire) para a ampliação das equidades socioeconômicas e para a retomada e preservação do equilíbrio ambiental, no chamado ecossocialismo.

A denúncia a respeito dos impactos ambientais em escala local e em escala global caracterizam uma das grandes contribuições em relação ao desafio ambiental a ser enfrentado. Neste sentido, o ecossocialismo é uma corrente de pensamento e de ação ecológica a buscar elementos no marxismo, mas consciente a ponto de evitar as problemáticas relacionadas ao produtivismo.

Entre as principais definições de ecossocialismo, podemos destacar aquela elaborada por James O'Connor, a qual define “...como ecossocialistas as teorias e os movimentos que aspiram a subordinar o valor de troca ao valor de uso, organizando a produção em função das necessidades sociais e das exigências do meio ambiente" (O'CONNOR apud LÖWY, 2014. p. 45). Um exemplo interessante disso é o uso da energia solar para o abastecimento de aglomerados urbanos, como na cidade de Diu, na Índia. Onde 100\% dos 56 000 moradores recebem energia solar em suas residências e ainda redistribuem o excedente para outras localidades. Ou ainda, o trem com painéis fotovoltaicos instalados no seu teto, na cidade de Delhi, também na Índia. Iniciativa esta que alia o uso de uma energia limpa ao uso do transporte coletivo de massa. Esta última iniciativa citada evita o lançamento de aproximadamente 9 toneladas métricas de dióxido de carbono na atmosfera por ano.

O fato é que o ecossocialismo se alicerça em dois pilares, o primeiro que o modelo consumista dos países capitalistas avançados, fundado numa lógica de acumulações ilimitadas (lucros, mercadorias...), do esgotamento de elementos naturais, do consumo acelerado, descomedido e ostentatório, da extrema concentração de riqueza e da destruição irresponsável e indiscriminada do meio ambiente não pode ser compartilhada para todo o conjunto do planeta, caso contrário, a crise generalizada em escala global.

O segundo elemento que sustenta as argumentações ecossocialistas se refere ao fato de que o atual modelo de progresso e a expansão das atividades econômicas baseadas na economia de mercado, com falsas esperanças de 
exploração infinita e agravamento contínuo das disparidades socioeconômicas são insustentáveis a longo prazo e ameaçam a sobrevivência de todos.

Assim, é cada vez mais necessária uma mudança drástica. Segundo Michel Löwy (2014, p.48):

\begin{abstract}
Certamente, a mudança radical diz respeito não apenas à produção, mas também ao consumo. Todavia, o problema da civilização burguesa/industrial não é - como pretendem em geral os ecologistas - "o consumo excessivo" da população, e a solução não é a "limitação" geral do consumo, notadamente nos países capitalistas avançados. É o tipo de consumo atual, fundado na ostentação, no desperdício, na alienação mercantil, na obsessão acumuladora, que deve ser questionado.
\end{abstract}

É preciso um grande conjunto de transformações transitórias rumo às práticas socialistas e participativas, a princípio localmente e mais adiante com a expansão das escalas de funcionamento. Mesmo com todas as possibilidades de críticas por parte de quem venha a afirmar que tais anseios são utópicos ou impalpáveis. Na realidade, seguindo os conselhos de um outro grande brasileiro e comunista declarado: "É preciso sonhar, senão as coisas não acontecem" (Oscar Niemeyer). Nesse ritmo do sonho podemos ser embalados pela união dos movimentos de trabalhadores (vermelhos) e os movimentos ecológicos (verdes) e, necessariamente, ampliar a solidariedade com os oprimidos e os explorados das paragens do sul.

As práticas nocivas ao meio ambiente, a falta de consideração pelas epistemologias do sul e porque não, as práticas racistas; muitas delas ainda agravadas pela interceccionalidade com o machismo, estão diretamente ligadas diretamente a este modelo explorador e voltado para a manutenção de privilégios e concentração da riqueza. Assim:

[...] todo ser que é dominado não é respeitado em seu próprio ser, nas suas virtualidades e potencialidades, porquanto é considerado somente nas suas qualidades que podem servir ao dominador. Dominação é, sempre, em algum grau, a negação do outro, o que é válido tanto para povos, para etnias, para grupos e/ou classes sociais como para a natureza. (PORTO-GONÇALVES, 2012, p. 21).

É imprescindível romper com esses grilhões da dominação capitalista financeira e industrial. Desta feita, temos observado que as práticas coloniais, as industriais e as neoliberais têm sido extremamente danosas em relação à 
natureza, incluindo àquelas executadas contra povos inteiros, faz-se necessário o estudo e práticas ecossocialistas e decoloniais. Além do que, é preciso dar mais oportunidades de superação das mazelas socais e também visibilidade às epistemologias dos territórios marginalizados. Como forma de reconstrução de suas identidades e produção de novas ações e objetos, mais justos e positivos para os povos dessas paragens do sul e para o restante da humanidade.

Desse modo, é extremamente necessário a associação do ecossocialismo com a prática de uma "pedagogia engajada" ou ainda, uma "pedagogia decolonial", como nos ensina bell Hooks (Gloria Watkins), com fortes influências de Paulo Freire, também no sentido do sulear.

O ecossocialismo numa perspectiva qualitativa pode eliminar os deprimíveis desperdícios e a veneração aos produtos inúteis e ostentatórios. Massivamente propagandeados por um sem-fim de meios publicitários, indutores da maquiagem das utilidades/futilidades e alimentadores do consumismo. Este imbuído do desejo de ter, leva o sujeito a imensos sacrifícios somente para realizar um acúmulo de objetos ("bens") potencialmente perdedores de valor, como os telefones celulares e os periféricos de informática. Os quais logo param de funcionar, a bateria para de recarregar ou são superados por uma versão mais moderna, mais completa, mais veloz, com uma câmera frontal, com duas câmeras frontais ou ainda câmera frontal angular. Enfim, uma série de novidades, transformadas em vontades (desejos) pelas estratégias publicitárias, numa sociedade com forte ideário burguês.

O combate ao referido ideário não é fácil, principalmente porque muitas vezes as reinvindicações dos movimentos ecológicos são distorcidas e até manipuladas em prol de um determinado tipo de consumo rotulado como consciente; mas que, na realidade, continua sendo ambientalmente irresponsável.

Mesmo cientes de possíveis cooptações ameaçadoras da lógica do capital. Existem demandas urgentes para a sobrevivência, as quais poderiam também se configurar também em ponto de convergência entre os objetivos ambientalistas e de outros movimentos sociais. Como, por exemplo, destaca Löwy (2014, p.55): 
- a promoção de transportes públicos - trens, metrôs, ônibus, bondes - baratos ou gratuitos como alternativa para o abafamento e a poluição das cidades e dos campos pelo carro individual e pelo sistema de transportes rodoviários;

- a luta contra o sistema de dívida e os "ajustes" ultraliberais impostos pelo FMI e pelo Banco Mundial aos países do Sul, com consequências sociais e ecológicas dramáticas: desemprego em massa, destruição das proteções sociais e das culturas de víveres, destruição dos recursos naturais para a exportação [...] .

A continuidade da exploração realizada pelos países mais ricos sobre os mais pobres, com destaque em relação aos da América Latina, tem sido mecanismo de manutenção da miséria e da exclusão entre os mais pobres. Principalmente por meio dos mecanismos associados à dívida externa.

Desse modo, conforme se encontra em (GEO 3, 2002:41, 44 e 50), citado por Porto Gonçalves (2016, p. 79)

[...] a dívida dos países latino-americanos, que era de US $\$ 46,3$ bilhões em 1971, atingira, em 1999, US\$ 982 bilhões, mesmo tendo sido pagos US\$ 739 bilhões somente no período de 1982 a 1996 ! Um crescimento da dívida em 21 vezes, entre 1971 e 1999, enquanto, no mesmo período a população passou de 176 milhões, em 1970, para 391 milhões de habitantes em 2000 , um crescimento de pouco mais de duas vezes! Enfim, a dívida per capita passou de US\$263 para US\$2.511 no período considerado.

Como os ataques e as consequências do sistema capitalista opressor (explorador) no qual vivemos são múltiplas. As abordagens precisam ser intersecionais, na medida em que os danos ambientais atingem aqueles e aquelas que já sofrem com outros problemas, como a fome, a falta de acesso à água potável, a poluição do ar, o racismo, o machismo...

Uma alternativa que vislumbramos a esse tipo de progresso irresponsável e altamente destrutivo que aí está, é o ecossocialismo. Uma opção que envolva uma série de práticas políticas e econômicas voltadas a sanar as necessidades de fato, nos sentidos socioeconômicos e do equilíbrio ambiental.

Segundo O’Connor apud Löwy (2014, p.72) “[...] a meta do socialismo ecológico é uma nova sociedade fundada na racionalidade ecológica, no controle democrático, na igualdade social e na supremacia do valor de uso sobre o valor de troca[...]". Para isso é necessária a transformação dos processos produtivos e não, simplesmente negar os avanços científicos, mas encontrar meios; principalmente por meio de processos decisórios 
participativos e de um planejamento verdadeiramente democrático. Para assim, evitar situações como a do Japão em relação à decisão tomada em 2012, de abandonar a energia nuclear até 2040. Lamentavelmente, tal decisão só aconteceu após a catástrofe na usina nuclear de Fukushima, em março de 2011. E, mais lamentável ainda foi que, em 2015, mesmo com muitos protestos contrários por parte da população daquele país, o governo japonês resolveu retomar o uso da energia nuclear.

Desse modo, percebemos que o consumo e a produção de um modo geral precisam ser realizados pelos conjuntos mais amplos da sociedade. Não apenas pelos conglomerados financeiros globais. Para isso, também são necessárias soluções quanto às questões do emprego do trabalhador, por meio, inicialmente da redução da jornada de trabalho. Até mesmo para esse trabalhador ter uma clara ampliação no tempo em que ele pode se dedicar ao estudo e à participação nas atividades e decisões gerais.

Sem que todas estas estratégias sejam associadas ao planejamento soviético de Stalin. Pois este, sem dúvida, estava bem distante de corresponder a um planejamento verdadeiramente democrático e harmonioso em relação à natureza.

No que se refere ao planejamento democrático dentro do ecossocialismo pressupõe-se diferentes escalas de planejamento. Local, regional, nacional e planetário, conforme as necessidades demandadas por cada nível. Assim,

O conjunto da população se interrogaria então a respeito da gratuidade do transporte público, de um imposto especial pago pelos proprietários de carros para subvencionar o transporte público, da subvenção da energia solar a fim de torna-la competitiva em relação à energia fóssil, da redução da jornada de trabalho para trinta ou 25 horas semanais ou menos, mesmo que isso acarretasse redução na produção. (LÖWY, 2014, p.83)

A decisão estaria nas mãos de vários atores sociais e certamente, com a ampliação dos conhecimentos a respeito das consequências dos atos nocivos ao meio ambiente e também das possibilidades decisórias, a maioria dos consumidores não aprovaria os atuais tempos de obsolescência dos produtos. A qual chega a afrontar a inteligência das pessoas com verdadeiras astúcias quanto ao previsível mau funcionamento do produto. 
Certamente que, "[...]. É impossível conceber a construção de uma nova sociedade sem que a maioria do povo tenha atingido uma grande consciência socialista e ecológica graças às suas lutas, à sua autoeducação e à sua experiência social[...]" (LÖWY, 2014, p.84). Neste sentido, é cada vez mais pertinente 0 papel do educador ambiental crítico, transformador e emancipatório nesta árdua tarefa de propagar a práxis necessária à devidas transformações esperadas e já anunciadas pelo ecossocialismo.

As transformações de amplo espectro, como aquelas sonhadas e propagadas pelos ecossocialistas precisam de um bom tempo de maturação e implementação na esfera da realidade presente e futura. Pois, exige uma séria de tomadas de decisões que afetam a construção de uma consciência ecológica, aliada a um conjunto de práticas socioeconômicas mais justas e equânimes. Além do mais, o embate ou a disputa com aquilo que está posto aí não é nada fácil. Haja vista que,

[...] técnicas da informação (por enquanto) são apropriadas por alguns Estados e por algumas empresas, aprofundando assim os processos de criação de desigualdades. É desse modo que a periferia do sistema capitalista acaba se tornando ainda mais periférica, seja porque não dispõe totalmente dos novos meios de produção, seja porque lhe escapa a possibilidade de controle. (SANTOS, 2000, p.38)

O conjunto de mudanças necessárias envolve alterações nas atuais racionalidades, a transformação da maneira como os elementos da sociedade lida entre si e como poderiam ser desenvolvidos no ecossocialismo. Neste sentido, uma nova racionalidade ambiental é urgente!

Dessa maneira, apresenta-se a necessidade de descontruir a racionalidade econômica, abrindo novas perspectivas para a construção de uma racionalidade ambiental orientada por um ecossocialismo democrático e sustentável. (LEFF, 2006, p.61)

Aqui se pode fazer uma reflexão em relação aos destinos da humanidade, por meio de um dos assuntos mais intrigantes quando se trata do futuro, é o caso da inteligência artificial. A qual tem sido estimulada pelas grandes corporações mundiais somente no intuito da acumulação de dinheiro e do aumento da obsolescência do ser humano. No livro Life 3.0: Being Human in the Age of Artificial Intelligence" (2017), do físico e professor do MIT, Max Tegmark, é uma relevante referência para a discussão sobre os impactos 
da Inteligência Artificial (IA). No livro; o professor questiona, por exemplo, como garantir o crescimento da prosperidade através da automação, sem deixar as pessoas sem emprego e renda e sem aumentar a exclusão social? Ou ainda, como evitar corrida armamentista em armas autônomas letais (robôs assassinos)? Portanto, é necessária a construção de uma racionalidade ambiental, a diminuir as esferas de incertezas acerca da busca e alcance da felicidade por um número maior de seres humanos, em suas especificidades e saberes.

A racionalização da sustentabilidade abre a possibilidade de construir um novo paradigma produtivo, fundado nas potencialidades da natureza e na recuperação e no enriquecimento do conhecimento que ao longo da história desenvolveram diferentes culturas sobre o uso sustentável dos seus recursos ambientais. (LEFF, 2006, p. 408).

\section{Referências}

GUIMARÃES, Mauro. Educação Ambiental Crítica. In: Identidades da Educação Ambiental brasileira. Philippe Pomier Layrargues (coord.). Ministério do Meio Ambiente. Diretoria de Educação Ambiental. Brasília, 2004.

GUIMARÃES, Mauro. Armadilha paradigmática na Educação Ambiental. In: LOUREIRO, C.F.B.; LAYRARGUES, P.P.; CASTRO, R.S. de. (Orgs.) Pensamento complexo, dialética e educação ambiental. São Paulo: Cortez. 2006. p. 15-29.

GUIMARÃES, Mauro. A formação de educadores ambientais. 6.ed., Campinas: Papirus, 2010.

GUIMARÃES, Mauro. A dimensão ambiental na educação. 12. ed. Campinas: Papirus, 2015.

LEFF, Enrique. A Racionalidade ambiental: a reapropriação social da natureza. Tradução Luís Carlos Cabral. Rio de Janeiro. Civilização brasileira, 2006.

LÖWY, Michael. Ecologia e socialismo. São Paulo: Cortez, 2005.

LÖWY, Michael. O que é o ecossocialismo? 2ํeição. São Paulo, 2014.

LÖWY, Michael. Ecossocialismo e planejamento democrático. Crítica Marxista. São Paulo, n. 28, p. 35-50, 2009.

PORTO-GONÇALVES, Carlos Walter. O desafio ambiental. Organizador Emir Sader. 6ํe ed. Rio de Janeiro: Record, 2016. 
PORTO-GONÇALVES, Carlos Walter. A ecologia política na América Latina: reapropriação social da natureza e reinvenção dos territórios. INTERthesis, Florianópolis, SC, v. 9, n. 1, p.16-50, Jan./Jun, 2012. https://periodicos.ufsc.br/index.php/interthesis/article/view/25431

SANTOS, Milton. Por uma outra globalização: do pensamento único à consciência universal. Rio de Janeiro: Record, 2000

SANTOS, Milton. A Natureza do espaço - técnica e tempo, razão e emoção. São Paulo. Hucitec. 1996. 